\title{
Maternal alcohol and tobacco consumption and the association with their 9 to 14-year-old children's Body Mass Index
}

\section{Figueiredo, Rejane Augusta De Oliveira}

2017-07

Figueiredo , R A D O , Roos , E , Eriksson, J G , Simola-Strom , S \& Weiderpass , E 2017 , '

Maternal alcohol and tobacco consumption and the association with their 9 to 14-year-old children's Body Mass Index ' , Scandinavian Journal of Public Health , vol. 45 , no. 5 , pp. 503-510 . https://doi.org/10.1177/1403494817702264

http://hdl.handle.net/10138/297792

https://doi.org/10.1177/1403494817702264

publishedVersion

Downloaded from Helda, University of Helsinki institutional repository.

This is an electronic reprint of the original article.

This reprint may differ from the original in pagination and typographic detail.

Please cite the original version. 


\title{
Maternal alcohol and tobacco consumption and the association with their 9 to 14-year-old children's Body Mass Index
}

\author{
REJANE AUGUSTA DE OLIVEIRA FIGUEIREDO ${ }^{1}$, \\ EVA ROOS ${ }^{1,2}$, JOHAN G. ERIKSSON ${ }^{1,3}$, \\ SABINA SIMOLA-STRÖM ${ }^{1}$ \& ELISABETE WEIDERPASS ${ }^{1,4,5,6}$
}

\begin{abstract}
${ }^{1}$ Folkhälsan Research Center, Helsinki, Finland, ${ }^{2}$ Department of Public Health, University of Helsinki, Helsinki, Finland, ${ }^{3}$ Department of General Practice and Primary Healthcare, University of Helsinki and Helsinki University Hospital, Helsinki, Finland, ${ }^{4}$ Department of Medical Epidemiology and Biostatistics, Karolinska Institutet, Stockholm, Sweden, ${ }_{5}^{5}$ Department of Research, Cancer Registry of Norway, Oslo, Norway, and ${ }^{6}$ Department of Community Medicine, Faculty of Health Sciences, University of Tromsø, The Arctic University of Norway, Tromsø, Norway.
\end{abstract}

\begin{abstract}
Aims: Little is known about impact of maternal alcohol and tobacco consumption on adolescents' body size. The purpose of this study was to evaluate whether maternal alcohol or tobacco consumption is associated with their children's body size in adolescence, assessed by Body Mass Index (BMI). Methods: This study was conduct in subjects recruited into the Finnish Health in Teens cohort (Fin-HIT) between 2011 and 2014. A total of 4525 subjects aged between 9 and 14 years and their mothers or female adults responsible for the children were analysed. Relative risks (RR) and $95 \%$ confidence intervals (CI) were estimated using Multinomial Logistic Regression. Results: Most children were normal weight (74.5\%), $10.6 \%$ were underweight and $14.9 \%$ were overweight or obese. Among mothers, $50.6 \%$ were never smokers, $35.7 \%$ were former smokers, and $13.7 \%$ were current smokers. Alcohol consumption was classified by Alcohol Use Disorders Identification Test (AUDIT), 12.7\% were abstainers (score=0), 65.0\% were low-moderate drinkers (scores $1-4$ ) and $22.3 \%$ were harmful drinkers (scores $\geqslant 5$ ). There were statistically significant associations between currently smoking mothers and children's overweight $(\mathrm{RR}=1.36$; 95\% $\mathrm{CI}: 1.05-1.76)$. There was an inverse association between maternal former smoking and children's underweight $(\mathrm{RR}=0.70$; $\mathrm{CI}$ : 0.56-0.87) compared with never smoker mothers. Among children in puberty, abstainer mothers were more likely to have underweight children compared with low-moderate mothers ( $R R=1.57 ; 95 \%$ CI: 1.03-2.41). Conclusions: Current smoker mothers were associated with children's overweight and former-smoker mothers were inversely associated with the children's underweight. Being an abstainer mother was associated with the children's underweight in puberty stage. If other studies confirm these results, public health interventions aiming at healthy weight of adolescents should target the whole family, not only the adolescents themselves.
\end{abstract}

Key Words: Overweight, underweight, alcohol, tobacco, adolescents, mother, obesity, epidemiology, cohort, Finland

\section{Introduction}

Overweight and obesity are important global public health problems for adults, but also for children and adolescents. Worldwide, the number of overweight or obese children and adolescents up to 18 years old has increased by $47 \%$ from 1980 to 2013 [1]. In Finland the estimated prevalence of overweight and obesity in children in 2006 was $10 \%$ in boys and $18 \%$ in girls [2]. While there are several available studies on overweight and obesity in teenagers, studies on underweight are less common, in particular in high-income

Correspondence: Rejane Augusta de Oliveira Figueiredo, Folkhälsan Research Center, Biomedicum 1 Helsinki, PB 63 (Haartmansgatan 8), 00014 University of Helsinki, Finland. E-mail: rejane.figueiredo@helsinki.fi

Date received 15 November 2016; reviewed 28 February 2017; accepted 8 March 2017

(C) Author(s) 2017

Reprints and permissions: sagepub.co.uk/journalsPermissions.nav DOI: $10.1177 / 1403494817702264$

journals.sagepub.com/home/sjp 
countries, as underweight is considered to be a somewhat more important problem in low and middleincome countries. Recent studies estimated the prevalence of underweight adolescents in the European countries to be approximately $10 \%$ [3].

Obesity in childhood is associated with pulmonary, cardiovascular, gastrointestinal and metabolic diseases, among other health consequences, both in the short and long term $[4,5]$. Several types of cancers, psychosocial and orthopaedic problems in adulthood may also be increased among obese children and adolescents [4]. Conversely, underweight in childhood is associated with short stature, increased morbidity and mortality, and pre-menopausal breast cancer in adulthood [6].

Some risk factors for obesity in adolescence are well established, such as lack of physical activity, poor eating patterns, inadequate sleep and genetic susceptibility $[4,7]$. Several studies have shown that parental socioeconomic status influences adolescents' underweight or overweight, as well as the patterns of alcohol and tobacco use in adolescence and adulthood [8]. Alcohol consumption has been reported to be directly associated with overweight in adults, while smoking cessation is associated with overweight, especially in male former smokers [9]. Although tobacco use by parents during pregnancy has been associated with increased risk of overweight in adolescence, few studies have been published so far on the association between parental tobacco and/or alcohol consumption during the offspring's teenage years and the adolescent's weight in the same time period [10].

The purpose of this study was to evaluate whether maternal consumption of alcohol or tobacco is associated with their children's weight status in adolescence, assessed by Body Mass Index (BMI) groups.

\section{Methods}

This study was conducted within the framework of the Finnish Health in Teens cohort (Fin-HIT), whose participants were recruited in 2011-2014. In total 11,523 subjects in early adolescence, aged 9-14 years old (henceforth denoted children) and 6081 adults responsible for those children participated in the study. Adolescents were recruited from schools in Southern, Middle and Northern Finland. The response rate of the whole study was approximately $30 \%$. The majority of adult participants in the study were women $(88.5 \%)$, so in the present study we evaluated baseline information for 4525 children who had BMI measurements and also alcohol and tobacco information from their female caretakers. For these 4525 female caretakers there was information on family relationship for 3300 participants, in which 99.5\% were the biological mothers of the children. Therefore, to not lose a considerable number of participants, assuming that most are biological mothers, we took into the study all female caretakers (from now on denoted only as mothers). Details of the cohort can be found at www.finhit.fi/for-researchers. The Fin-HIT study was approved by Coordinating Ethics Committee of the Hospital District of Helsinki and Uusimaa, Finland.

For children, anthropometric measures (height in meters (m), weight in kilograms (kg)) were obtained in a standardized way by trained field workers. Height was measured with a portable stadiometer and weight with portable and daily calibrated digital scales. Age in years and gender, both for mothers and children, and language spoken by children at home (Finnish, Swedish and others) was obtained from consent form or questionnaires, and confirmed by record linkages with the National Population Information System at the Population Register Centre.

Information on the mothers' educational attainment and maternal tobacco and alcohol consumption was obtained by a standardized questionnaire. Stage of puberty was self-reported by the adolescents through Tanner stage pictograms including different breast development stages for girls and different stages of pubic hair development for boys and girls. Weight and height of mothers were self-reported. The mothers' alcohol consumption was classified according to the Alcohol Use Disorders Identification Test (AUDIT) [11], which is a validated instrument to identify individuals with hazardous patterns of alcohol consumption consisting of 10 questions with total scores varying from 0 to 40. AUDIT's total scores were then categorized into abstainers (score 0 ), low-moderate drinkers (score 1-4), and harmful drinkers (score $\geqslant 5$ ). Although a score $\geqslant 8$ has been used to identify harmful or hazardous drinkers in several published studies, we adopt the score $\geqslant 5$ to indicate greater likelihood of drinking in an unhealthy or harmful way (denominated henceforth as harmful drinkers), since studies have shown that in women this score should be lower [12]. Tobacco consumption was categorized as never, former and current smoker. Children's BMI (weight in kg divided by height in $\mathrm{m}^{2}$ ) was categorized as underweight, normal weight and overweight or obese according to Cole and Lobstein Classification [13].

\section{Statistical analysis}

Categorical variables among BMI groups were compared using Chi-square tests. The association between the maternal alcohol or tobacco consumption and the 
children's BMI groups was estimated through relative risks (RR) and 95\% confidence intervals (CI 95\%) by Multinomial Logistic Regression, as BMI was evaluated in three categories. As when the event of interest is common (incidence over than 10\%) logistic regression models may lead to overestimated results, we also conducted Modified Poisson Regression models with robust error variance to estimate $\mathrm{RR}$ and $\mathrm{CI}$ 95\%, comparing normal weight with overweight and underweight groups. Given that the results were very similar using both methods, we present only the results estimated by Multinomial Logistic Regression to avoid multiple test problems.

Analyses comparing maternal tobacco and alcohol consumption were adjusted for children's age and gender, maternal age, educational attainment, maternal $\mathrm{BMI}$ (in $\mathrm{kg} / \mathrm{m}^{2}$ ), and language spoken at home.

Analyses were stratified by children's gender, puberty stage (pre-puberty and puberty) and the women's educational attainment in two categories: low (to high school graduate or technical qualification) and high (academic or university degree). For all stratified analysis the interaction effect was assessed using the Likelihood Ratio test, comparing models with and without the respective terms of interaction.

Missing data were found for mothers only for educational attainment $(n=26)$ and BMI $(n=7)$. For these variables we applied multiple imputation with the PROC MI procedure in version 9.4 of SAS statistical software (SAS Institute, Inc., Cary, North Carolina) and included these participants with missing data in the final analyses. For puberty stage we had 856 missing data. Since this variable was used only in stratified analysis, not in adjusted models, we did not include this variable in the multiple imputation procedure. All statistical analyses were conducted using SAS version 9.4 statistical software and we adopted a $5 \%$ statistical significance level.

\section{Results}

Of the 4525 children included, $52.0 \% \quad(n=2351)$ were girls and $48.0 \%(n=2174)$ boys. Their average age was $11.1( \pm 0.8)$ years, ranging from 9 to 14.7 years. Most children were normal weight $(74.5 \%$; $n=3,373), 10.6 \% \quad(n=479)$ were underweight and $14.9 \%(n=673)$ were overweight or obese. The category of obese children was too small $(2.6 \%)$ to allow analysis separately from overweight; therefore all results will be presented combined for overweight and obesity. The proportion of boys and girls was similar in the normal weight and overweight groups; however, in the underweight group there was a higher proportion of girls $(59.1 \% ; n=283)$ compared with $40.9 \%$ boys $(n=196)$ (Table I).

Among mothers, 58.1\% $(n=2625)$ were normal weight, $1.9 \%(n=84)$ were underweight and $40.0 \%$ $(n=1809)$ were overweight or obese. The average maternal age was 42.0 ( \pm 5.3) years, and the age range was $25-69$ years. Most mothers were never smokers $(50.6 \%, n=2288), 35.7 \%$ were former smokers $(n=1616)$, and $13.7 \%$ were current smokers $(n=621)$. Most mothers $(65.0 \% ; n=2943)$ were low to moderate drinkers, $12.7 \%$ were abstainers $(n=573)$ and $22.3 \%$ were harmful drinkers $(n=1009)$. There are more mothers with low educational attainment in the overweight and obese group $(55.5 \% ; n=371)$ compared with $47.1 \%(n=225)$ in underweight group and with $44.9 \%(n=1506)$ in normal weight group (Table I).

Mothers who smoke had a higher risk of having an overweight or obese child (adjusted $\mathrm{RR}=1.36$; 95\% CI: 1.05-1.76). There was an inverse association between former smoking mothers and children's underweight ( $R R=0.70$; 95\% CI: 0.56-0.87) (Table II).

Results are also reported separately by gender, educational attainment (Table III) and puberty stage (Table IV). The results were not evaluated separately by gender, since there was no statistically significant interaction between maternal alcohol or tobacco consumption and children's gender $(p=0.200$ and $p=0.220$, respectively). There was statistically significant interaction for tobacco related to mothers' educational attainment $(p=0.004)$, but no interaction for alcohol and mothers' educational attainment $(p=0.054)$. There was also an interaction between children's puberty stage and maternal alcohol or tobacco consumption $(p<0.001)$. The inverse association between former smoking mothers and children's underweight were observed in mothers with high educational attainment and also among children in pre-puberty stages $(p<0.05)$ (Table III and IV). The increased risk of having overweight children was most remarkable in the subgroup of mothers with low educational attainment $(\mathrm{RR}=1.40 ; 95 \% \mathrm{CI}$ : 1.02-1.93) (Table III). Among children having reached puberty at the study time point, it was observed that abstainer mothers had an increased risk of having underweight children $(R R=1.57 ; 95 \%$ CI: 1.03-2.41) compared with mothers with low or moderate alcohol consumption (Table IV).

\section{Discussion}

In this study we report that the maternal consumption of tobacco and alcohol was associated with the children's BMI groups. 
Table I. Characteristics of children and mothers by categories of the children's Body Mass Index (BMI) groups.

\begin{tabular}{|c|c|c|c|c|c|c|c|c|c|c|}
\hline & & \multicolumn{6}{|c|}{ Children's BMI groups } & \multicolumn{2}{|l|}{ Total } & \multirow[t]{3}{*}{$p$-value ${ }^{\mathrm{a}}$} \\
\hline & & \multicolumn{2}{|c|}{ underweight } & \multicolumn{2}{|c|}{ normal } & \multicolumn{2}{|c|}{$\begin{array}{l}\text { overweight }+ \\
\text { obese }\end{array}$} & \multirow[t]{2}{*}{$n$} & \multirow[t]{2}{*}{$\%$} & \\
\hline & & $n$ & $\%$ & $n$ & $\%$ & $n$ & $\%$ & & & \\
\hline \multicolumn{11}{|c|}{ Characteristics of children } \\
\hline \multirow[t]{2}{*}{ Gender } & girl & 283 & $59.1 \%$ & 1742 & $51.6 \%$ & 326 & $48.4 \%$ & 2351 & $52.0 \%$ & 0.001 \\
\hline & boy & 196 & $40.9 \%$ & 1631 & $48.4 \%$ & 347 & $51.6 \%$ & 2174 & $48.0 \%$ & \\
\hline \multirow[t]{2}{*}{ Puberty } & pre-puberty & 191 & $48.4 \%$ & 1051 & $38.5 \%$ & 173 & $32.4 \%$ & 1415 & $38.7 \%$ & $<0.001$ \\
\hline & puberty & 204 & $51.6 \%$ & 1676 & $61.5 \%$ & 361 & $67.6 \%$ & 2241 & $61.3 \%$ & \\
\hline \multicolumn{11}{|c|}{ Characteristics of mothers } \\
\hline \multirow{2}{*}{$\begin{array}{l}\text { Education } \\
\text { attainment }\end{array}$} & low education attainment & 225 & $47.1 \%$ & 1506 & $44.9 \%$ & 371 & $55.5 \%$ & 2102 & $46.7 \%$ & $<0.001$ \\
\hline & high education attainment & 253 & $52.9 \%$ & 1846 & $55.1 \%$ & 298 & $44.5 \%$ & 2397 & $53.3 \%$ & \\
\hline \multirow[t]{3}{*}{ BMI groups } & underweight & 22 & $4.6 \%$ & 60 & $1.8 \%$ & 2 & $0.3 \%$ & 84 & $1.9 \%$ & $<0.001$ \\
\hline & overweight & 82 & $17.1 \%$ & 894 & $26.5 \%$ & 235 & $35.0 \%$ & 1211 & $26.8 \%$ & \\
\hline & obese & 33 & $6.9 \%$ & 371 & $11.0 \%$ & 194 & $28.9 \%$ & 598 & $13.2 \%$ & \\
\hline \multirow{3}{*}{$\begin{array}{l}\text { Tobacco } \\
\text { consumption }\end{array}$} & never smokers & 282 & $58.9 \%$ & 1699 & $50.4 \%$ & 307 & $45.6 \%$ & 2288 & $50.6 \%$ & $<0.001$ \\
\hline & former smokers & 142 & $29.6 \%$ & 1232 & $36.5 \%$ & 242 & $36.0 \%$ & 1616 & $35.7 \%$ & \\
\hline & current smokers & 55 & $11.5 \%$ & 442 & $13.1 \%$ & 124 & $18.4 \%$ & 621 & $13.7 \%$ & \\
\hline \multirow{3}{*}{$\begin{array}{l}\text { Alcohol } \\
\text { consumption } \\
\text { (AUDIT score) }\end{array}$} & low-moderate drinkers $(1-4)$ & 322 & $67.2 \%$ & 2197 & $65.1 \%$ & 424 & $63.0 \%$ & 2943 & $65.0 \%$ & 0.040 \\
\hline & abstainers $(0)$ & 73 & $15.2 \%$ & 416 & $12.3 \%$ & 84 & $12.5 \%$ & 573 & $12.7 \%$ & \\
\hline & harmful drinkers $(\geqslant 5)$ & 84 & $17.5 \%$ & 760 & $22.5 \%$ & 165 & $24.5 \%$ & 1009 & $22.3 \%$ & \\
\hline
\end{tabular}

aresults for Chi-square test.

Table II. Risk relative (RR) and confidence intervals (CI) for mothers' alcohol and tobacco consumption related to children's Body Mass Index (BMI) groups.

\begin{tabular}{|c|c|c|c|c|c|c|c|c|c|c|c|c|}
\hline & \multicolumn{12}{|c|}{ Children's BMI groups ${ }^{a}$} \\
\hline & \multicolumn{2}{|c|}{ Normal } & \multicolumn{2}{|c|}{ Underweight } & \multicolumn{3}{|c|}{$\begin{array}{l}\text { Comparison normal } \times \\
\text { underweight }\end{array}$} & \multicolumn{2}{|c|}{$\begin{array}{l}\text { Overweight } \\
+ \text { obese }\end{array}$} & \multicolumn{3}{|c|}{$\begin{array}{l}\text { Comparison normal } \times \\
\text { overweight }\end{array}$} \\
\hline & $n$ & $\%$ & $n$ & $\%$ & $\mathrm{RR}$ & $(95 \% \mathrm{CI})$ & $p$-value & $n$ & $\%$ & $\mathrm{RR}$ & $(95 \% \mathrm{CI})$ & $p$-value \\
\hline \multicolumn{13}{|l|}{ Mothers' tobacco consumption } \\
\hline never smokers & 1699 & $50.4 \%$ & 282 & $58.9 \%$ & 1 & & & 307 & $45.6 \%$ & 1 & & \\
\hline former smokers & 1232 & $36.5 \%$ & 142 & $29.6 \%$ & 0.70 & $(0.56-0.87)$ & 0.001 & 242 & $36.0 \%$ & 1.05 & $(0.87-1.28)$ & 0.603 \\
\hline current smokers & 442 & $13.1 \%$ & 55 & $11.5 \%$ & 0.82 & $(0.59-1.14)$ & 0.243 & 124 & $18.4 \%$ & 1.36 & $(1.05-1.76)$ & 0.021 \\
\hline \multicolumn{13}{|l|}{$\begin{array}{l}\text { Mothers' alcohol consumption } \\
\text { (AUDIT score) }\end{array}$} \\
\hline low-moderate drinkers $(1-4)$ & 2197 & $65.1 \%$ & 322 & $67.2 \%$ & 1 & & & 424 & $63.0 \%$ & 1 & & \\
\hline Abstainers (0) & 416 & $12.3 \%$ & 73 & $15.2 \%$ & 1.27 & $(0.96-1.68)$ & 0.097 & 84 & $12.5 \%$ & 0.94 & $(0.72-1.23)$ & 0.630 \\
\hline harmful drinkers $(\geqslant 5)$ & 760 & $22.5 \%$ & 84 & $17.5 \%$ & 0.82 & $(0.63-1.06)$ & 0.131 & 165 & $24.5 \%$ & 1.00 & $(0.81-1.23)$ & 0.969 \\
\hline
\end{tabular}

aVariables in the models: Children's gender, age, language; Mothers' age, BMI, education attainment, tobacco, alcohol.

Current smoking among the mothers was associated with children's overweight or obesity. Similar results regarding the influence of maternal smoking on the weight of their children have been reported previously in a large multicentre study [14]; however, that study did not report results according to BMI category. Our study was also consistent with the results by Huerta et al. [15] among Israeli children that showed parental smoking being associated with children's overweight. The mechanism by which tobacco consumption by parents affects adolescents' weight is unclear, although it may reflect a more unhealthy family lifestyle or parenting style in general [14]. Future studies are needed to understand the mechanisms by which tobacco smoking among parents, in particular mothers, affect body weight in adolescents. Epigenetic mechanisms may have some influence in the development of overweight and obesity $[16,17]$. There is epidemiological and experimental evidence suggesting that tobacco exposure during pregnancy and during the offspring's early childhood activate epigenetic mechanisms that may 
Impact of maternal alcohol and tobacco consumption on adolescents' BMI

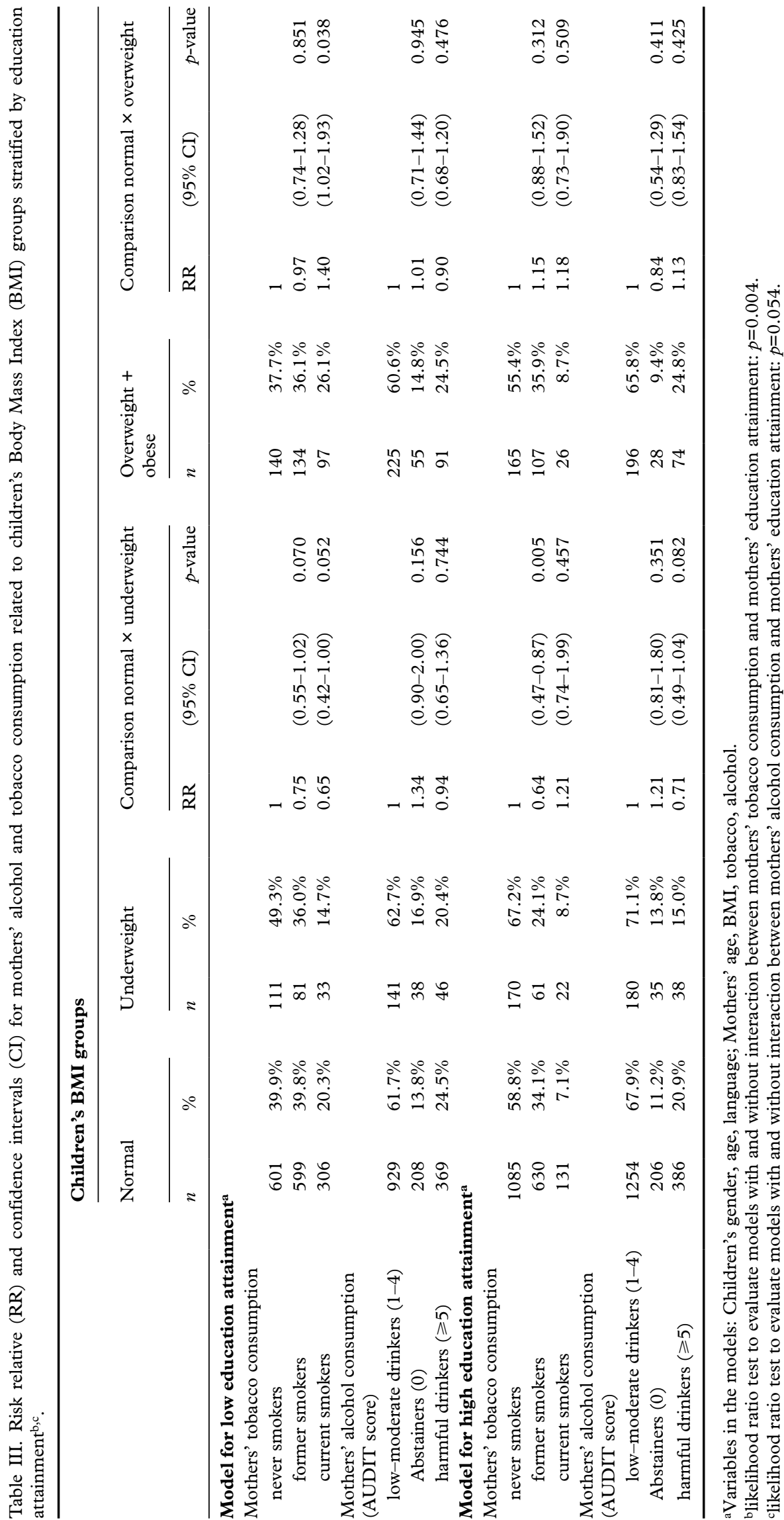


Table IV. Risk relative (RR) and confidence intervals (CI) for the mothers' alcohol and tobacco consumption related to children's Body Mass Index (BMI) groups stratified by puberty stage $\mathbf{b}^{\mathbf{b}, \mathbf{c}}$.

\begin{tabular}{|c|c|c|c|c|c|c|c|c|c|c|c|c|}
\hline & \multicolumn{12}{|c|}{ Children's BMI groups } \\
\hline & \multicolumn{2}{|c|}{ Normal } & \multicolumn{2}{|c|}{ Underweight } & \multicolumn{3}{|c|}{$\begin{array}{l}\text { Comparison normal } \times \\
\text { underweight }\end{array}$} & \multicolumn{2}{|c|}{$\begin{array}{l}\text { Overweight } \\
+ \text { obese }\end{array}$} & \multicolumn{3}{|c|}{$\begin{array}{l}\text { Comparison normal } \times \\
\text { overweight }\end{array}$} \\
\hline & $n$ & $\%$ & $n$ & $\%$ & $\mathrm{RR}$ & $(95 \% \mathrm{CI})$ & $p$-value & $n$ & $\%$ & $\mathrm{RR}$ & $(95 \% \mathrm{CI})$ & $p$-value \\
\hline \multicolumn{13}{|c|}{ Model for children in pre-puberty } \\
\hline \multicolumn{13}{|c|}{$\begin{array}{l}\text { Mothers' tobacco } \\
\text { consumption }\end{array}$} \\
\hline never smokers & 497 & $47.3 \%$ & 110 & $57.6 \%$ & 1 & & & 68 & $39.3 \%$ & 1 & & \\
\hline former smokers & 422 & $40.2 \%$ & 61 & $31.9 \%$ & 0.66 & $(0.46-0.93)$ & 0.018 & 69 & $39.9 \%$ & 1.16 & $(0.80-1.68)$ & 0.443 \\
\hline current smokers & 132 & $12.6 \%$ & 20 & $10.5 \%$ & 0.82 & $(0.47-1.43)$ & 0.479 & 36 & $20.8 \%$ & 1.51 & $(0.92-2.49)$ & 0.102 \\
\hline \multicolumn{13}{|l|}{$\begin{array}{l}\text { Mothers' alcohol consumption } \\
\text { (AUDIT score) }\end{array}$} \\
\hline low-moderate drinkers $(1-4)$ & 683 & $65.0 \%$ & 126 & $66.0 \%$ & 1 & & & 104 & $60.1 \%$ & 1 & & \\
\hline Abstainers (0) & 145 & $13.8 \%$ & 29 & $15.2 \%$ & 1.14 & $(0.72-1.80)$ & 0.576 & 19 & $11.0 \%$ & 0.79 & $(0.46-1.36)$ & 0.396 \\
\hline harmful drinkers $(\geqslant 5)$ & 223 & $21.2 \%$ & 36 & $18.8 \%$ & 0.95 & $(0.63-1.45)$ & 0.813 & 50 & $28.9 \%$ & 1.20 & $(0.81-1.77)$ & 0.359 \\
\hline \multicolumn{13}{|c|}{ Model for children in pubertya } \\
\hline \multicolumn{13}{|l|}{ Mothers' tobacco consumption } \\
\hline never smokers & 865 & $51.6 \%$ & 120 & $58.8 \%$ & 1 & & & 173 & $47.9 \%$ & 1 & & \\
\hline former smokers & 598 & $35.7 \%$ & 59 & $28.9 \%$ & 0.74 & $(0.53-1.03)$ & 0.078 & 122 & $33.8 \%$ & 0.92 & $(0.70-1.20)$ & 0.522 \\
\hline current smokers & 213 & $12.7 \%$ & 25 & $12.3 \%$ & 0.92 & $(0.57-1.50)$ & 0.741 & 66 & $18.3 \%$ & 1.37 & $(0.96-1.97)$ & 0.085 \\
\hline \multicolumn{13}{|l|}{$\begin{array}{l}\text { Mothers' alcohol consumption } \\
\text { (AUDIT score) }\end{array}$} \\
\hline low-moderate drinkers (1-4) & 1097 & $65.5 \%$ & 133 & $65.2 \%$ & 1 & & & 239 & $66.2 \%$ & 1 & & \\
\hline Abstainers (0) & 182 & $10.9 \%$ & 33 & $16.2 \%$ & 1.57 & $(1.03-2.41)$ & 0.036 & 42 & $11.6 \%$ & 0.85 & $(0.58-1.27)$ & 0.431 \\
\hline harmful drinkers $(\geqslant 5)$ & 397 & $23.7 \%$ & 38 & $18.6 \%$ & 0.86 & $(0.59-1.28)$ & 0.462 & 80 & $22.2 \%$ & 0.84 & $(0.62-1.13)$ & 0.243 \\
\hline
\end{tabular}

aVariables in the models: Children's gender, age, language; Mothers' age, BMI, education attainment, tobacco, alcohol.

blikelihood ratio test to evaluate models with and without interaction between mothers' tobacco consumption and children's puberty stage: $p<0.001$.

clikelihood ratio test to evaluate models with and without interaction between mothers' alcohol consumption and children's puberty stage: $p<0.001$.

lead to obesity and endocrine dysfunction among the offspring [18]. A recent study showed that maternal smoking during pregnancy influenced methylation patterns in offspring, assessed through the cord blood of newborns [19].

We found an inverse association between mothers being a former smoker and underweight among their children. We did not find studies in the literature about parental smoking cessation and its impact on their children's body weight in adolescence. However, studies show that former smokers learn to handle stress without tobacco need, they have an increased feeling of well-being and improved mental health compared with current smokers [20]. Thus, it is plausible that parental smoking cessation may have an overall impact on the family's well-being, including avoiding children becoming underweight. Some studies suggest that smoking is associated with depression [21]. Maternal depression and other mental health issues have been reported to affect children's nutritional status, adolescents' behaviour and lower BMI among girls at ages 8-9 [22,23]. Mothers who are former smokers may have a lower probability of depression, which may influence their children's BMI.

Among children having reached puberty we found that abstainer mothers had an increased risk of having underweight children compared with mothers with low or moderate alcohol consumption. We used the AUDIT questionnaire to evaluate the pattern of alcohol consumption in the mothers. The advantage of AUDIT is that it is a simple instrument with only 10 questions and has proven sensitivity and specificity to identify unhealthy behaviours related to alcohol consumption [12]. Finland is a country with high per capita consumption of alcohol and low percentage of abstainers as compared with other European countries [24]. In our study, where participants were recruited in 2011-2014, we found that $12.7 \%$ of the mothers were abstainers, and this result is similar to the 2010 estimates for Finland with $10.7 \%$ of women being abstainers [24]. Alcohol intake is an established risk factor for several diseases in humans $[25,26]$, while the impact of alcohol on cardiovascular health is still debated [27]. Abstainers may have a different lifestyle, including 
dietary patterns, than alcohol drinkers. While most studies have shown that alcohol consumption is associated with an increased risk of mental health problems, some studies have found that light to moderate alcohol consumption is associated with decreased anxiety and depression [28,29]. In other studies maternal depression has been associated with offspring malnutrition $[22,30]$. More studies need to be carried out to evaluate a possible association between parental alcohol consumption, maternal depression and weight in adolescents.

Our study has several strengths: it is based on a large population of children and their mothers. We were able to explore associations between maternal alcohol and tobacco consumption not only with children's overweight and obesity but also children's underweight, while considering other important potential confounders and effect modifiers such as children's age and gender, maternal age, educational attainment and BMI. Our study has several limitations: we could not separate the analysis of children in the overweight and obese group due to small numbers of obese adolescents. We lack information on why mothers had never consumed alcohol, the amount of tobacco consumed, smoking duration and time since quitting among former smokers. We also lack information on children's birthweight and if the children consumed tobacco and alcohol themselves, although given their young age it is highly unlikely that they did so in Finland.

In conclusion, this study shows that mothers' consumption of tobacco and alcohol is associated with their children's BMI in adolescence. Current smoking mothers were associated with children's overweight and former-smoker mothers were inversely associated with children's underweight. Among children having reached puberty, being an abstainer mother was associated with the children's underweight. If our results are confirmed by other studies, they provide further arguments that potential public health interventions in order to maintain a healthy weight in adolescents need to target entirely families, and not only adolescents themselves.

\section{Funding}

The author(s) disclosed receipt of the following financial support for the research, authorship, and/or publication of this article: This work was supported by Folkhälsan Research Foundation; Academy of Finland [grant number 250704]; Life and Health Medical Fund [grant number 1-23-28]; The Swedish Cultural Foundation in Finland [grant number 15/0897]; Signe and Ane Gyllenberg Foundation [grant number 37-1977-43]; and Yrjö Jahnsson Foundation [grant number 11486].

\section{Conflict of interest}

The authors declare that there is no conflict of interest.

\section{References}

[1] $\mathrm{Ng} \mathrm{M}$, Fleming $\mathrm{T}$, Robinson $\mathrm{M}$, et al. Global, regional, and national prevalence of overweight and obesity in children and adults during 1980-2013: A systematic analysis for the Global Burden of Disease Study 2013. Lancet 2014;384(9945):766-81.

[2] Vuorela N, Saha MT ad Salo M. Prevalence of overweight and obesity in 5- and 12-year-old Finnish children in 1986 and 2006. Acta Paediatr Int $\mathcal{F}$ Paediatr 2009;98(3):507-12.

[3] Yi Lin, Mouratidou T, Vereecken C, et al. Dietary animal and plant protein intakes and their associations with obesity and cardio-metabolic indicators in European adolescents: The HELENA cross-sectional study. Nutr $\mathcal{F}$ [Internet] 2015;14(1):1-11. Available from: http://search.ebscohost. com/login. aspx?direct $=$ true $\& d b=a 9 h \& A N=101914324 \&$ si te $=$ ehost-live $\% 5$ Cnhttp://content.ebscohost.com/ContentServer.asp? $\mathrm{T}=\mathrm{P} \& \mathrm{P}=\mathrm{AN} \& \mathrm{~K}=101914324 \& \mathrm{~S}=\mathrm{R} \& \mathrm{D}=\mathrm{a} 9 \mathrm{~h} \& \mathrm{E}$ bscoContent $=$ dGJyMMvl7ESep684y9f3OLCmr02eprFSrq $\mathrm{q} 4 \mathrm{Sq}+\mathrm{WxWXS} \&$ ContentCustomer=dGJyMPGqt1 Czr

[4] Xu S and Xue Y. Pediatric obesity: Causes, symptoms, prevention and treatment (review). Exp Ther Med 2016;11(1):15-20.

[5] Twig G, Yaniv G, Levine H, et al. Body-Mass Index in 2.3 million adolescents and cardiovascular death in adulthood. $N$ Engl f Med 2016;374(25):2430-40.

[6] Lazzeri G, Rossi S, Pammolli A, et al. Underweight and overweight among children and adolescents in Tuscany (Italy). Prevalence and short-term trends. F Prev Med Hyg 2008;49(1):13-21.

[7] Gurnani M, Birken C and Hamilton J. Childhood obesity: Causes, consequences, and management. Pediatr Clin North Am 2015;62(4):821-40.

[8] World Health Organization. WHO report on the global tobacco epidemic, 2015. WHO: Geneva, 2015.

[9] León-Munõz LM, Gutiérrez-Fisac JL, Guallar-Castillón $\mathrm{P}$, et al. Contribution of lifestyle factors to educational differences in abdominal obesity among the adult population. Clin Nutr 2014;33(5):836-43.

[10] Wade KH, Skugarevsky O, Kramer MS, et al. Prospective associations of parental smoking, alcohol use, marital status, maternal satisfaction, and parental and childhood body mass index at 6.5 years with later problematic eating attitudes. Nutr Diabetes 2014;4(1):e100.

[11] Babor TF, Higgins-Biddle JC, Saunders John JB, et al. AUDIT. The Alcohol Use Disorders Identification Test. Guidelines for Use in Primary care. 2nd ed. Geneva, Switzerland, 2001.

[12] Reinert DF and Allen JP. The alcohol use disorders identification test: An update of research findings. Alcohol Clin Exp Res 2007;31(2):185-99.

[13] Cole TJ and Lobstein T. Extended international (IOTF) body mass index cut-offs for thinness, overweight and obesity. Pediatr Obes 2012;7(4):284-94.

[14] Braithwaite I, Stewart W, Hancox J, et al. Maternal postnatal tobacco use and current parental tobacco use is associated with higher body mass index in children and adolescents: An international cross-sectional study. BMC Pediatr 2015;15:220.

[15] Huerta M, Bibi H, Haviv J, et al. Parental smoking and education as determinants of overweight in Israeli children. Prev Chronic Dis [Internet]. 2006;3(2):A48. Available from: http://www.pubmedcentral.nih.gov/articlerender.fcgi?artid= 1563963\&tool $=$ pmcentrez\&rendertype $=$ abstract 
[16] Ambatipudi S, Cuenin C, Hernandez-Vargas H, et al. Tobacco smoking-associated genome-wide DNA methylation changes in the EPIC study. Epigenomics 2016;8(5):599-618.

[17] Quarta C, Schneider R and Tschöp MH. Previews epigenetic ON/OFF switches for obesity. Cell 2016;164(3):341-2.

[18] Lisboa PC, de Oliveira E and de Moura EG. Obesity and endocrine dysfunction programmed by maternal smoking in pregnancy and lactation. Front Physiol 2012;3 NOV(November):1-9.

[19] Joubert BR, Felix JF, Yousefi P, et al. DNA methylation in newborns and maternal smoking in pregnancy: Genome-wide consortium meta-analysis. Am f Hum Genet 2015;680-96.

[20] Piper ME, Kenford S, Fiore MC, et al. Smoking cessation and quality of life: Changes in life satisfaction over 3 years following a quit attempt. Ann Behav Med 2012;43(2):262-70.

[21] Bakhshaie J, Zvolensky MJ and Goodwin RD. Cigarette smoking and the onset and persistence of depression among adults in the United States: 1994-2005. Compr Psychiatry 2015;60:142-8.

[22] Ashaba S, Rukundo GZ, Beinempaka F, et al. Maternal depression and malnutrition in children in southwest Uganda: A case control study. BMC Public Health [Internet] 2015;15(1):1303. Available from: http://www.pubmedcentral.nih.gov/articlerender.fcgi?artid=4693407\&tool=pmcen trez\&rendertype $=$ abstract

[23] Duarte C, Shen S, Wu P, et al. Maternal depression and child BMI: Longitudinal findings from a US sample. Pediatr Obesity 2012;7(2):124-33.
[24] Anderson P, Møller L and Galea G. Alcohol in the European Union. WHO Regional Office Europe: Copenhagen, 2012.

[25] Boffetta P and Hashibe M. Alcohol and cancer. Lancet Oncol 2006;7:149-56.

[26] Chacko KR and Reinus J. Spectrum of alcoholic liver disease. Clin Liver Dis 2016;20(3):419-27.

[27] Roerecke $M$ and Rehm J. Alcohol consumption, drinking patterns, and ischemic heart disease: A narrative review of meta-analyses and a systematic review and meta-analysis of the impact of heavy drinking occasions on risk for moderate drinkers. BMC Med 2014;12(1):182.

[28] Bellos S, Skapinakis P, Rai D, et al. Cross-cultural patterns of the association between varying levels of alcohol consumption and the common mental disorders of depression and anxiety: Secondary analysis of the WHO Collaborative Study on Psychological Problems in General Health Care 5. Drug Alcohol Depend. 2013;133(3):825-31.

[29] Bellos S, Skapinakis P, Rai D, et al. Longitudinal association between different levels of alcohol consumption and a new onset of depression and generalized anxiety disorder: Results from an international study in primary care. Psychiatry Res [Internet]. 2016;243:30-4. Available from: http:// dx.doi.org/10.1016/j.psychres.2016.05.049

[30] Harpham T, Huttly S, De Silva MJ, et al. Maternal mental health and child nutritional status in four developing countries. I Epidemiol Community Health [Internet]. 2005;59(12):1060-4. Available from: http://jech.bmj.com/ content/59/12/1060.short 